\title{
Analysis of Etiological Factors of Dyslipidemia -A Case Control Study
}

\author{
Research Article
}

\author{
Sadhana Misar Wajpeyi ${ }^{*}$ \\ 1. Associate Professor, MGACH \& RC, Datta Meghe Institute of Medical \\ Sciences (Deemed to be University), Wardha.
}

\begin{abstract}
Introduction: Dyslipidemia is not mentioned in Ayurveda but it can be correlated with Medoroga. Nidanparivarjana is the main treatment principle of Ayurveda. The lifestyle modification is a part of the management for patients with Dyslipidemia, regardless of pharmacologic intervention. Aims and Objectives: To study the etiological factors of Dyslipidemia related to Ahar and Vihar (Dietary \& Behavioral regimen). Material And Methods: Analytical case control study was conducted in which total 100 subjects were randomly selected from OPD and IPD of Kayachikitsa Department of MGACH \& RC, Salod (H), Wardha. They were randomly divided into case and control group. Each subject was exposed to case proforma. Case proforma was made in such a way that it included probable etiological factors related to Dyslipidemia. Observation And Results: Statistical analysis showed that Dyslipidemia was significantly related with unhealthy dietary habits, Dyslipidemia present in family, obesity, alcohol consumption, smoking, tobacco, tea and diabetes mellitus. Discussion \& Conclusion: The findings showed that all risk factors are not contributing in pathogenesis of disease but they differ in each individual. It is not necessary that all the etiological factors are needed in the pathogenesis of Dyslipidemia but it can be cause due to presence of some of them.
\end{abstract}

Key Words: Atherosclerosis, Dhamanipratichaya, Dyslipidemia, Medoroga, Lipids, Lipoproteins.

\section{Introduction}

Dyslipidemia refers to the abnormal amounts of the lipids (e.g., cholesterol and/or fat) in the blood. Dyslipidemia is a disorder of lipoprotein metabolism, including lipoprotein over production or deficiency. Dyslipidemia may be manifested by elevation of total cholesterol, low Density Lipoprotein cholesterol LDL and triglycerides concentration and decrease in high density lipoprotein cholesterol (HDL) concentration in the blood i.e. presence of abnormal serum lipid concentration of one or more types (1).

There is no direct reference of Dyslipidemia in Ayurvedic classics. It can be included under santarpanjanya vyadhias "Medoroga". In many research studies hyperlipidemia is termed by different nomenclature, e.g. Rasagata SnehaVriddhi (increase in lipids in plasma), Rasa Raktagata SnehaVriddhi (increase in the lipids in plasma and blood), Medovriddhi (generalized lipid increase),

\section{* Corresponding Author:}

\section{Sadhana Misar Wajpeyi}

Associate Professor, MGACH \& RC,

Datta Meghe Institute of Medical Sciences

Wardha. Maharashtra. India.

Email id-sadhanamisar@gmail.com
Medoroga or Medodosha (obesity), Aam Medo Dhatu (abnormally formed adipose tissue) (2).

Agni is responsible for all metabolic activities in the body. Agnimandya leads to production of Ama (undigested food). Ama is the main cause of all metabolic disorders in Ayurveda. This accumulated Ama is capable of obstructing the metabolic pathways and causing diseases. Cholesterol is considered as one such product that originates due to metabolic impairment in the alimentary tract and fat tissue (Meda).

When there is derangement of Medodhatwagni, then it will lead to excess accumulation of abnormal quantities of poshakamedodathu in rasa. This excess accumulation of abnormal quantities of poshakamedodathu in rasa dhatu resembles hyperlipidaemia of modern medicine. The consequence of $\mathrm{such}$ increase in Poshakamedodhatu leads to disorders such as Dhamanipratichaya described by Acharya Charak in Kaphajananatmajavyadhi (3).

In India, there has been an alarming increase in the prevalence of CVD over the past two decades that accounts for $24 \%$ of all deaths among adults aged 25-69 years (4). Prevalence of hypercholesterolemia according to Indian Council of Medical Research (ICMR) Integrated Disease 
Surveillance varies from $10-15 \%$ in rural to $25-30 \%$ in urban populations (5).Treatment of Dyslipidemia can reduce the risk of heart disease by approximately $30 \%$ over a 5 -year period. (6).

\section{Need of study}

The prevalence of Dyslipidemia is high and increases continuously in many developing countries as a result of the westernization of diet, obesity, aging of population, reduced physical activity, and other adverse lifestyle changes (7).Dyslipidemia is one of the most important and modifiable risk factors for cardiovascular diseases, which is also a major cause of morbidity and leads to mortality worldwide $(8,9,10)$. Nidanparivarjana is the main treatment principle of Ayurveda. So if we are well acquainted with etiological factors of Dyslipidemia we can avoid it and keep ourselves healthy. The lifestyle modifications are also a part of the treatment regimen for patients with Dyslipidemia, regardless of pharmacological intervention. Hence, this study was undertaken to evaluate the factors responsible in development of Dyslipidemia.

\section{Aims and objectives}

Aim

\section{Objectives}

Study of etiological factors of Dyslipidemia.

To study the risk factors related to Ahar (Dietary regimen).

To study the risk factors related to Vihar (Behavioral regimen)

\section{Materials and methods}

Place of Study - OPD and IPD of Kayachikitsa Department of MGACH \& RC, Salod (H), Wardha

Ethical clearance - It was obtained from Institutional Ethics committee of Datta Meghe Institute of Medical sciences, Sawangi (IEC No. DMIMS (DU)/ IEC/ 2017-18/6355).

- Study Design: Observational Study

- Study Type: Analytical case control study

- Sample size: Total -100 (each group 50)

- Grouping: Two Groups each of 50

- Group A-Control Group

- Group B- Case Group

\section{Inclusion criteria}

- Age group of 20-70 years irrespective of sex.

- Patients not having any systemic illness

- Diagnosed \& confirmed cases of Dyslipidemia according to National Cholesterol Education Program and Adult Treatment Panel III (NCEP:ATPIII, 2001) as follows- i) Total cholesterol $\geq 200 \mathrm{mg} / \mathrm{dL}$ and/or

ii) LDL from 130 to $189 \mathrm{mg} / \mathrm{dL}$ and/or

iii) Sr.Triglycerides between 150 to $499 \mathrm{mg} / \mathrm{dL}$ and/or

iv) $\mathrm{Sr} . \mathrm{HDL}<40 \mathrm{mg} / \mathrm{dL}$.

\section{Exclusion criteria}

- Patient having systemic illness like Tuberculosis, Carcinoma, Endocrine disorders

- and Renal or Liver disorder.

- Drug induced Dyslipidemia

- Bed ridden patients.

- Subjects those who are unable to answer the questionnaire.

Group A- Case definition- Cases between age group of 20-70 years not on any medications were screened for Lipid profile after 12 hours fasting and if reports are within normal level then taken under control group.

Group B- Case definition- Known cases of dyslipidemia between age group of 20-70 years.

\section{Selection of subjects}

Patients of dyslipidemia came to the Outpatient Department of Kayachikitsa of Mahatma Gandhi Ayurved College Hospital and Research Centre, Salod (H), Wardha, from October, 2007, to July, 2009 were selected randomly for study. The study group comprised 50 Diagnosed \& confirmed cases of Dyslipidemia according to National Cholesterol Education Program and Adult Treatment Panel III (NCEP:ATPIII, 2001) between 20-70 years of age and an equal number of healthy volunteers, taken as controls, who consented to undergo the required investigations. The patients of both the groups were selected matched for age and sex. Detailed history was obtained from cases and controls with regard to family history, prior treatment history, physical activity, and other lifestyle factors including tobacco and alcohol exposure. Special case proforma was prepared and each subject was examined according to the case proforma. Data related to weight, height, body mass index (BMI) and blood pressure was recorded. BMI was calculated as weight $(\mathrm{kg}) /[$ height $(\mathrm{mt})]^{2}$.Institutional Ethical Committee clearance was obtained prior to the commencement of the study.

Fasting serum lipid profile was estimated using Vitros 250, fully automated analyzer, after a period of 12-14 hours of fasting.

\section{Investigations}

- Lipid profile-

- Total Cholesterol

- Triglycerides

- High density lipoproteins

- Low density lipoproteins

- Very low density lipoproteins

- Blood Glucose Level. 


\section{Observations and results}

Assessment will be done by comparing the factors related to Dyslipidemia in both the groups.

Statistical analysis was done by using descriptive and inferential statistics using chi square test and Student's unpaired t test and software used in the analysis were SPSS 22.0 version and Graph Pad Prism 7.0 version and $\mathrm{p}<0.05$ is considered as level of significance.

In Group A, 14 (28\%) patients belonged to age group above 60 years followed by $13(26 \%)$ belonged to 41-50 years, $10(20 \%)$ belonged to 51-60 years of age, $8(16 \%)$ belonged to $21-30$ years and $5(10 \%)$ patients belonged to 31-40 years. In group B, 17 (34\%) patients belonged to $51-60$ years followed by $11(20 \%)$ belonged to $31-40$ years, $10(20 \%)$ patients belonged to more than 60 years of age, $8(16 \%)$ patients belonged to $41-50$ years whereas only $4(8 \%)$ patients belonged to $21-30$ years. Comparison of both groups regarding age was not significant.

In Group A, 29 (58\%) patients were female and remaining was male. In Group B 32 (64\%) patients were female and remaining was male. Comparison of both groups was not significant.

Regarding occupation, in group A, 15 (30\%) patients were housewives, 14 (28\%) patients were doing service, $10(20 \%)$ patients were labourer, $8(16 \%)$ were farmer and $3(6 \%)$ patients were businessmen. In group B, 19 (38\%) patients were doing service, 17(34\%) patients were housewives, $7(14 \%)$ patients were labourer , 4(8\%) patients were farmer and 3(6\%) patients were businessmen. Comparison of both groups was not significant.

Regarding marital status, in both groups $43(86 \%)$ patients were married and remaining were unmarried. Comparison of both groups was not significant.

According to socio-economic status, in Group A, 36(72\%) patients and in Group B 35(70\%) patients were from middle socio-economic status and remaining were from poor socio-economic status. No any patient from high socio-economic status was found in both groups. Comparison of both groups showed not significant.

Family history of Dyslipidemia was present in $18(36 \%)$ patients and absent in 32(64\%) patients in Group A whereas family history of Dyslipidemia was present in $29(58 \%)$ patients and absent in 21(42\%) patients of Group B. Comparison of two groups was significant with $(\mathrm{P}=0.027)$ value.

In Group A, 14 (28\%) patients had Kaphapittaja prakruti whereas in Group B, 14(28\%) patients had vatapittaja prakruti and 16 patients had kaphavataja and kaphapittaja prakruti. Comparison of both groups was significant with $\mathrm{P}=0.0001$ value.

In Group A, sama Agni was observed in $25(50 \%)$ patients whereas mandaagni observed in
14(28\%) patients. In Group B, sama Agni was present in $32(64 \%)$ patients whereas manda Agni was present in $15(30 \%)$ patients. Comparison of both groups was not significant.

In Group A, 25(50\%) patients had BMI $\left(\mathrm{kg} / \mathrm{m}^{2}\right)$ between $25-29.9 \mathrm{~kg} / \mathrm{m}^{2}$ and $12(24 \%)$ patients had BMI more than $30 \mathrm{~kg} / \mathrm{m}^{2}$. In Group B, 25(50\%) patients had BMI more than $30 \mathrm{~kg} / \mathrm{m}^{2}$ and $20(40 \%)$ patients had BMI between $25-29.9 \mathrm{~kg} / \mathrm{m}^{2}$. In Group A, 13(26\%) patients and in Group B, 5(10\%) patients had normal BMI within 18.5-24.9 kg/m². Comparison of both groups was significant with $\mathrm{P}=0.013$ value.

In Group A, 30(60\%) patients had healthy dietary habits and 20(40\%) patients had unhealthy dietary habits. In Group B, 37(74\%) patients had unhealthy dietary habits (atisnigdha, guru, atimadhur and mixed diet) and 13(26\%) patients had healthy dietary habits. Comparison of both groups was significant with $\mathrm{P}=0.0006$ value.

In Group A, 33(66\%) patients had regular nidra (sleep) and 17(34\%) patients had irregular nidra (sleep) whereas in Group B, 34 (68\%) patients had regular and $16(32 \%)$ patients had irregular nidra (sleep). Comparison of both groups was not significant.

In Group A, stress was present in 21(42\%) patients whereas in Group B stress was present in 35 (70\%). Comparison of both groups was significant with $\mathrm{P}=0.0001$ value

In Group A, 31(62\%) patients had no any type of vyasan (habit/addiction). In Group B 22(44\%) patients have no any type of vyasan (habit/addiction). whereas remaining $28(56 \%)$ patients had varying type of vyasan (habit/addiction) like alcohol, tobacco, smoking and tea. Comparison of both groups was significant with $\mathrm{P}=0.044$ value.

In Group A, 25(50\%) patients and in Group B $29(58 \%)$ patients were not doing any type of physical exercise. Remaining patients were doing exercise like walking and yoga. Comparison of both groups was not significant.

Systolic and diastolic blood pressure in both groups was normal and comparison of both groups was not significant.

In Group A, 9 (18\%) patients had Diabetes mellitus and 41(82\%) patients had no Diabetes mellitus. In Group B, 23(46\%) patients had Diabetes mellitus whereas 27(54\%) patients had no Diabetes mellitus. Comparison of both groups was significant with $\mathrm{P}=0.0027$ value.

In Group A, 12(24\%), 25(50\%) and 13(26\%) patients had sthul (obese), madhyam (medium) and krusha (emaciated) akruti (physique) respectively whereas in Group B, 25(50\%), 22(44\%) and 3(6\%) patients had sthul, madhyam and krush aakruti respectively. Comparison of both groups was significant with $\mathrm{P}=0.004$ value. 
In Group A, average Blood Sugar level was $116.62 \pm 47.45$ and in Group B, average Blood Sugar level was $140.84 \pm 51.24$. Comparison was significant with $\mathrm{t}$ and $\mathrm{p}$ value $(\mathrm{t}=2.45, \mathrm{p}=0.016)$

In Group A, average total cholesterol level was $163.84 \pm 20.86$ and in Group B, average total cholesterol level was 218.36 \pm 30.44 . Comparison was significant with $\mathrm{t}$ and $\mathrm{p}$ value $(\mathrm{t}=10.44, \mathrm{p}=0.0001)$.

In Group A, average triglyceride level was $122.82 \pm 26.29$ and in Group B, average triglyceride level was $170.08 \pm 66.44$. Comparison was significant with $\mathrm{t}$ and $\mathrm{p}$ values $(\mathrm{t}=4.67, \mathrm{p}=0.0001)$.

In Group A, average LDL level was $96.86 \pm 15.28$ and in Group B, average LDL level was 147.86 \pm 31.39 .Comparison of both groups was significant with $t$ and $p$ values $(t=10.32, p=0.0001)$.

In Group A, average HDL level was 34.14 \pm 4.19 and in Group B, average HDL level was $34.88 \pm 6.42$. Comparison of both groups was not significant with $\mathrm{t}$ and $\mathrm{p}$ values $(\mathrm{t}=0.68, \mathrm{p}=0.47)$.

In Group $A$ average VLDL level was $27.02 \pm 6.98$ and in Group B, average VLDL level was $31.72 \pm 11.68$.Comparison of both groups was not significant with $\mathrm{t}$ and $\mathrm{p}$ values $(\mathrm{t}=2.44, \mathrm{p}=0.016)$.

\section{Discussion}

Dyslipidemia is a metabolic disorder related to abnormal fat metabolism. Dyslipidemia is one of the risk factors which cause atherosclerosis, stroke and cardiovascular diseases (CVDs). But it can be prevented by adopting healthy dietary habits and lifestyle. These two measures can also be adopted to correct the Dyslipidemia.

Lipid abnormalities were calculated as total cholesterol (TC) $>200$, serum triglyceride $>150$, low density lipoprotein (LDL) $>130 \mathrm{mg} / \mathrm{dl}$, high density lipoprotein (HDL) $<40$. Cholesterol/ HDL ratio $>4.5$ according to the criteria set by the National Cholesterol Education Program-Adult Treatment Panel III (NCEP ATP III).(11) Statistical analysis showed that, in Group B (Case group) majority of the patients (34\%) belonged to the age group 51-60 years. In research conducted by Padhar Chhaganbhai et.al. found maximum patients (32\%) were between $40-50$ years age group, which matches with result of this study.(12) In research conducted by Jyoti BJ et.al. they observed Dyslipidemia in majority subjects belonged to 20 to 29 years $(51.5 \%$, $\mathrm{n}=17$ ) followed by age group 30 to 39 and 50 to 59 $(18.2 \%, \mathrm{n}=6$ in each of them) indicating the shift of predominance from older age group to younger age group, which is not similar to the findings in this study. (13) In group B, female were more $(58 \%)$ in number. Research conducted by Pooja and Bhatted observed male dominance $63.33 \%$ in their study, which did not match with this study. They found service class patients $(38 \%)$ and the housewives $(34 \%)$ more in number in their study. They observed a greater number of patients
(70\%) from middle socioeconomic class, these findings had similarity with results of this study (14).Mandagni and Aam formation are two main pathological factors of Medoroga described in Ayurveda. But in this study Maximum patients (64\%) had sama Agni. Family history of Dyslipidemia was present in maximum patients (58\%) of group B (case group), which is major risk factor of Dyslipidemia. Medoroga is mainly found in kaphadushti. Maximum patients (28\%) belonged to kaphajavataja prakruti in group B. Majority patients $(40 \%)$ had Body Mass Index (BMI) in the range of $25-29.9 \mathrm{~kg} / \mathrm{m}^{2}$ and $(50 \%)$ had $\mathrm{BMI} \geq 30 \mathrm{~kg} / \mathrm{m}^{2}$ (normal range- $18-24 \mathrm{~kg} / \mathrm{m}^{2}$ ) in group B. Manjiri Arun Nadkarni et.al. in their study found BMI greater than $25 \mathrm{~kg} / \mathrm{m}^{2}$ in $81.96 \%$ of patients, which shows similarity with results of this study (15). BMI more than $25 \mathrm{~kg} / \mathrm{m}^{2}$ is considered as obese and BMI $\geq 30 \mathrm{~kg} / \mathrm{m}^{2}$ is considered as severely obese, which is the major risk factor for Dyslipidemia. Maximum patients (90\%) had sthul prakruti (obesity) in group B. Most of the patients in group B had unhealthy dietary habits (74\%) atimadhur(excessive sweet), guru (heavy to digest), snigdha (oily) and mixed type of food. In research conducted by Shivam G Joshi et.al. found that majority of $(91.33 \%)$ patients had diet rich in Madhura Rasa, Snigdha Guna (70\%), Guru Guna (65\%), and SheetaVeerya $(63 \%)$. They observed more number of patients (68.33\%) had Vishamashana and Adhyashana, which are the major risk factors of Dyslipidemia (16). Indulgence in Kaphavardhakaahara leads to Medovriddhi and causes "Medoroga". Vyasan (Bad habits like alcohol consumption, smoking, tobacco and tea ) was present in maximum (56\%) number of patients in group B. Consumption of alcohol, smoking and tobacco are the major risk factors for Dyslipidemia as it interfere with fat metabolism and leads to Dyslipidemia. Majority of patients (58\%) were not adapted to any type of physical exercise in group B. Sedentary life is one of the major cause of obesity and Dyslipidemia. Stress was present in most of the patients (70\%) of group B, which is also risk factor for Dyslipidemia. Average Systolic Blood pressure was 126.20 \pm 9.66 and diastolic Blood pressure was $80.60 \pm 7.39$ in group B whereas Diabetes mellitus was present in majority of the patients (46\%) of group B. Diabetes mellitus is one of the risk factor of Dyslipidemia. Similar types of findings were reported by other researchers in their studies conducted on Dyslipidemia.

Swapnil S. Auti, conducted research study on Dyslipidemia and their study findings consists of most of the above mentioned etiological factors in their study (17).

Advanced age, sedentary lifestyle, lack of exercise, stress, obesity, unhealthy dietary habits, family history of Dyslipidemia, alcohol consumption, smoking, tobacco chewing, hypertension and Diabetes mellitus are the major risk factors for Dyslipidemia.(18). 
In this study statistical analysis showed that Dyslipidemia was significantly associated with unhealthy dietary habits, family history of Dyslipidemia, obesity, alcohol consumption, smoking, tobacco, tea and Diabetes mellitus. But the other factors like advanced age, sedentary lifestyle, lack of exercise, stress and hypertension are factors also related to cause Dyslipidemia. Hence from this study it can be concluded that it is not necessary that all the etiological factors are needed in the pathogenesis of Dyslipidemia but it can be cause due to presence of some of them. According to the factors found in this study it can be stated that patients having family history of Dyslipidemia, obesity, bad habits like alcohol consumption, smoking, tobacco and diabetes mellitus have high risk of Dyslipidemia and should be screened for early diagnosis. The lack of awareness about benefits of healthy diet and regular physical activity may increase the risk of Dyslipidemia which is one of the major risk factor for cardiovascular and cerebrovascular disorders. Hence, emphasis should be given on regular awareness programs on lifestyle modification and its benefits for reducing the risk of cardiovascular diseases. Screening programs for early detection of Dyslipidemia in populations having association with above mentioned etiology should be conducted so that it can be treated in early stage with lipid lowering drugs and life style modifications to reduce the risk of atherosclerosis.

\section{Conclusion}

The prevalence of metabolic disorders like Dyslipidemia is increasing day by day due to unhealthy, faulty dietary habits, sedentary lifestyle, stress, hypertension and Diabetes mellitus. From this study it can be concluded that advanced age, sedentary lifestyle, unhealthy dietary habits like consumption of excessive sweet, oily food, stress, obesity, hypertension, Diabetes mellitus are risk factors of Dyslipidemia. The findings of this study showed that all risk factors are not contributing in pathogenesis of disease but they differ in each individual. Factors like unhealthy dietary habits, bad habits like alcohol consumption, smoking, tobacco, obesity, Diabetes mellitus are major factors associated with Dyslipidemia. People should be made aware about these risk factors to avoid such type of causes and prevent these disorders. Screening of people having above risk factors also helps in early diagnosis and treatment of the disease.

Funding: No funding sources

Conflict of interest: None declared

Ethical approval: The study was approved by the institutional ethics committee

\section{References}

1. Braunwald E, FanciAS,Hauser SL, Kasper DL, Longo DL, Jameson JL, Harrison TR. Harrison's Principles of Internal Medicines, 12th International Edition.,New York: Mc Graw-Hill Medical Publishing Division,Vol. I, 2002.

2. Manjiri AN, Vyas SN, Baghel MS and Ravi shankar B. Randomized placebo controlled trial of Mustadighanavati in hyperlipidemia, AYU 2010; 31(3):287-93 (accessed on 22.05.2018 at 7.01pm)

3. Yadavji Trikamji Acharya, Charaka samitha with Ayurveda deepika Coemmentary of Sri Chakrapanidattha, Chowkamba Krishnadas Acadamy, Varanasi - 2004 - Sutra Sthana - 20/17

4. Sample Registration System (2007) Million Death Study: Preliminary Report on Causes of New Delhi: Registrar General of India, Death in India 20012003.( accessed on 18.4.2018 at 04.21pm)

5. SS Iyengar, Raman Puri, et al.'Lipid Association of India Expert Consensus Statement on Management of Dyslipidemia in Indians, Part 1"Journal of The Association of Physicians of India ,1st March, 2016,pg no. 9 .( accessed on 21.4.2018 at 10.13am)

6. Grundy SM, Cleeman JI, Merz CN, Brewer HB Jr, Clark LT, Hunninghake DB, Pasternak RC, Smith SC Jr, Stone NJ. Implications of recent clinical trials for the National Cholesterol Education Program Adult Treatment Panel III guidelines.J Am CollCardiol. 2004; 44: 720-732.(accessed on 17.10.2016 at $4.49 \mathrm{pm})$.

7. Fuentes R, Uusitalo T, Puska P, Tuomilehto J, Nissinen A. Blood cholesterol level and prevalence of hypercholesterolaemia in developing countries: a review of population-based studies carried out from 1979 to 2002. Eur J Cardiovasc PrevRehabil. 2003;10(6): 411-19. Google Scholar ( accessed on 17.102016 at $4.42 \mathrm{pm})$.

8. Murray CJ, Lopez AD. Mortality by cause for eight regions of the world: Global Burden of Disease Study. Lancet. 1997;349(9061):126976.PubMedView Article Google Scholar. ( accessed on 28.03 .2018 at $12.29 \mathrm{pm}$ ).

9. Groundy SM, Small LDL Atherogenic Dyslipidemia and the metabolic syndrome. Circulation (1997), 95: 1-4 [PubMed] ( accessed 29.03.2017 at $01.24 \mathrm{pm})$.

10. Haffnar M (1999) Diabetes, hyperlipidemia and coronary artery disease. Am J Cardio 183 (Suppl): 17F-21F [PubMed] ( accessed 27.08.2018 at $09.54 \mathrm{pm})$.

11. National Cholesterol Education Program (NCEP) Expert Panel on Detection, Evaluation, and Treatment of High Blood Cholesterol in Adults (Adult Treatment Panel III). Third report of the National Cholesterol Education Program (NCEP) expert panel on detection, evaluation, and treatment of high blood cholesterol in adults (Adult Treatment 
Panel III) final report.Circulation. 2002;106 (25):3143-421. (accessed on 17.03.2018 at $012.54 \mathrm{pm})$.

12. Padhar Bharatkumar Chhaganbhai, a comparative clinical study of tryoshnadiguggulu and lasuna in the management of Dyslipidemia, $\mathrm{J}$ of Ayurveda and Hol Med (JAHM).2015;3(5):3-20 . ( accessed on 21.03 .2018 at $10.24 \mathrm{pm})$.

13. Jyoti Bj, Kavita Mb, A Comparative Clinical Study On Efficacy Of Bhavita Amalaki Choorna And ShuddhaGuggulu In Dyslipidemia Jour. Of Ayurveda \& Holistic Medicine (July-August 2016), Volume-IV, Issue-IVPp.11-31 ( accessed on 22.05.2018 at 07.06pm).

14. Pooja B A, Bhatted SK. A standard controlled clinical study on Virechana Karma and LekhanaBasti in the management of Dyslipidemia (Medoroga). AYU 2016;37:32-7( accessed on 28.03.2018 at $12.34 \mathrm{pm})$.
15. Manjiri Arun Nadkarni et.al. Randomized placebocontrolled trial of MustadiGhanavati in hyperlipidemia Ayu. 2010 Jul-Sep; 31(3): 287-293. (accessed on 22.05.2018 at 7.01pm).

16. Joshi SG, Chandola HM, Dave AR. A comparative clinical study of Asanadi Ghanavati and GomutraHaritaki in KaphaMedoMargavarana (Dyslipidemia). AYU 2014;35:152-9(accessed on 28.03.2018 at 10.23pm).

17. Swapnil S. Auti et.al. Assessment of LekhanaBasti in the management of hyperlipidemia, Ayu. 2013 Oct-Dec; 34(4): 339-345. (accessed on 28.03.2018 at $12.34 \mathrm{pm})$.

18. Braunwald E, FanciAS,Hauser SL, Kasper DL, Longo DL, Jameson JL (editors).,Harrison TR. Harrison's Principles of Internal Medicines, 12th International Edition. In: New York: McGraw-Hill Medical Publishing Division,Vol. I, 2002. 